\title{
Increasing nitrogen rates in rice and its effect on plant nutrient composition and nitrogen apparent recovery
}

\author{
Juan Hirzel $^{1 *}$, and Francisco Rodríguez ${ }^{2}$
}

Rice (Oryza sativa L.) is one of the essential foods of the human diet; advances in agronomic crop management can improve productivity and profitability as well as reduce adverse environmental impacts. Nitrogen rates in Chile are generally based on crop yield without considering other agronomic factors. The objective of this experiment was to determine the effect of increasing $\mathrm{N}$ rates on plant nutrient composition and $\mathrm{N}$ apparent recovery in rice cultivated in five different locations in Chile. The five sites located in central Chile belong to one of the following soil orders: Inceptisol, Alfisol, and Vertisol; they were cropped in field conditions with 'Zafiro-INIA' rice fertilized with 0,80 , and $160 \mathrm{~kg} \mathrm{~N} \mathrm{ha}^{-1}$. Whole-plant total DM, macronutrient composition, and $\mathrm{N}$ apparent recovery efficiency (NARE) were determined at grain harvest. Results indicate that all evaluated parameters, with the exception of K concentration, were affected by the soil used. Nitrogen rates only affected total DM production and $\mathrm{P}, \mathrm{K}$, and $\mathrm{Mg}$ concentrations in plants. Phosphorus and $\mathrm{K}$ response decreased when $\mathrm{N}$ was added to some soils, which is associated with its chemical properties. Magnesium concentration exhibited an erratic effect, but it was not affected by the $\mathrm{N}$ rate in most soils. Nitrogen apparent recovery efficiency was not affected by the $\mathrm{N}$ rate and accounted for approximately $49 \%$ and $41 \%$ for 80 and $160 \mathrm{~kg} \mathrm{~N} \mathrm{ha}^{-1}$, respectively. Macronutrient composition was 5.1-7.7 g N, 1.3-1.8 g P, 5.4-10.8 g K, 1.68-2.57 g Ca, and 0.81-1.45 $\mathrm{g} \mathrm{Mg} \mathrm{kg}^{-1}$ of total DM.

Key words: Fertilization, nitrogen, Oryza sativa.

\section{INTRODUCTION}

Rice (Oryza sativa L.) is one of the essential foods of the human diet (Juliano, 1993; FAO, 2004). Advances in agronomic crop management such as weed control, new cultivars, and $\mathrm{N}$ fertilization can improve productivity and profitability as well as reduce adverse environmental impacts (Angus et al., 1994; De-Xi et al., 2007; Soon et al., 2007; Hirzel et al., 2011a). Nitrogen is the main nutrient associated with yield, but $\mathrm{N}$ management responds differently to rice type (indica or japonica associated with climate requirement and interaction with $\mathrm{N}$ nutrition), cultivar, geographic zone, and other crop practices (Angus et al., 1994; Ying et al., 1998; Bouman et al., 2007; De-Xi et al., 2007; Huang et al., 2008; Jing et al., 2008; Hirzel et al., 2011a). Similarly, fertilization management and genotype $\times$ environment interaction generate differences in plant nutrient composition (Mengel and Kirkby, 1987); they affect crop extraction, rice plant yield components,

${ }^{1}$ Instituto de Investigaciones Agropecuarias INIA, Av. Vicente Méndez 515, Chillán, Chile.

"Corresponding author (jhirzel@inia.cl).

${ }^{2}$ Universidad del Bío-Bío, Facultad de Educación y Humanidades, Chillán, Chile.

Received: 12 March 2013.

Accepted: 10 September 2013.

doi:10.4067/S0718-58392013000400009 and N use efficiency (Ying et al., 1998; Kapoor et al., 2008; Matsunami et al., 2009; Taylaran et al., 2009). At the same time, differences in nutrient compartmentalization in the rice plant (grain and residues) (Cordero-Vásquez and Murillo-Vargas, 1990) produce positive or negative effects on the nutrient balance of the soil-plant system for those productive systems in which plant residues are incorporated or extracted. Studies carried out in rice soils in Chile indicate a reduction in available fractions of $\mathrm{P}$, $\mathrm{K}, \mathrm{B}$, and $\mathrm{Zn}$ in the last $20 \mathrm{yr}$ (Hirzel and Cordero, 2011).

To adjust $\mathrm{N}$ rate in rice, it is important to know how much $\mathrm{N}$ was supplied by soil mineralization (Angus et al., 1994); this is highly dynamic over time, difficult to estimate, and represents only a very small fraction of total soil N (Scott et al., 2005; Wienhold, 2007). Several laboratory methods were developed with different coefficient adjustments to crop $\mathrm{N}$ response, $\mathrm{N}$ extraction, or grain yield (Waring and Bremner, 1964; Angus et al., 1994; Wilson et al., 1994; Scott et al., 2005; Sahrawat, 2006; Bushong et al., 2007; Hirzel et al., 2011b). These have generated local recommendations that cannot be easily applied to all cultivars, crop management, and regions of the world. The general concept to determine $\mathrm{N}$ rates is the relationship between yield potential ( $\mathrm{N}$ extraction) and mineralizable $\mathrm{N}$ as an inversely proportional function (Hirzel et al., 2011b). Chile has

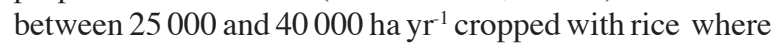


soil $\mathrm{N}$ supply capacity in paddy rice soils is determined by soil anaerobic incubations with constant shaking at $30{ }^{\circ} \mathrm{C}$ for $14 \mathrm{~d}$ (routine laboratory method). However, current development methodologies indicate a higher correlation between extracted $\mathrm{N}$ for field crops and soil mineralized $\mathrm{N}$ prior to cultivation with incubations without shaking at $20{ }^{\circ} \mathrm{C}$ for $21 \mathrm{~d}$ (Hirzel and Stolpe, 2013). In addition, Chilean paddy rice soils, in accordance with their physical and chemical properties, produced different responses to $\mathrm{N}$ rates and thus affecting grain yield and its components (Artacho et al., 2009; Hirzel et al., 2011a), as well as soil mineralized N (Hirzel et al., 2011b; Hirzel and Stolpe, 2013). On the other hand, the result of continuous genetic enhancement has created different cultivars that need adjusted agronomic management in which $\mathrm{N}$ fertilization is imperative. The objective of this study was to determine the effect of increasing $\mathrm{N}$ rates on whole-plant total DM production, whole-plant macronutrient concentration, and $\mathrm{N}$ apparent recovery efficiency (NARE) in five paddy rice soils in Chile.

\section{MATERIALS AND METHODS}

The study was carried out in south central Chile with a rice monocrop during the 2011-2012 season in five paddy rice soils including the Inceptisol, Alfisol, and Vertisol orders with the following soil series: Achibueno loam (fine, mixed, superactive, thermic Fluventic Xerochrepts), Quilmen loam (fine, mixed, thermic Typic Xerocherpts), Parral clay loam (fine, mixed, active, thermic Aquic Haploxeralfs), Quella1 clay loam (fine, smectitic, thermic Aquic Durixererts), and Quella2 clay loam (fine, smectitic, thermic Aquic Durixererts) (CIREN, 1997). The climate of the zone is Mediterranean characterized by high temperatures and low rainfall in summer and low temperatures and high rainfall in winter. Soil samples with 20 subsamples were collected in cores of 0 to $20 \mathrm{~cm}$ depth before crop establishment and subsequently characterized for physical and chemical properties (Table 1). The procedures to analyze soil characteristics were performed in the laboratory of the Instituto de Investigaciones Agropecuarias (INIA), Chile (Sadzawka et al., 2006). To determine mineralized $\mathrm{N}\left(\mathrm{N}-\mathrm{NH}_{4}{ }^{+}\right)$, a soil anaerobic incubation was performed $(5 \mathrm{~g}$ soil and $12.5 \mathrm{~mL}$ distilled water placed in a test tube and incubated without shaking at $20^{\circ} \mathrm{C}$ for $21 \mathrm{~d}$ ) (Hirzel and Stolpe, 2013). Soil ammonium extracts were obtained by adding $12.5 \mathrm{~mL} 2 \mathrm{M} \mathrm{KCl}$ to the soil tubes; the mixture was shaken for $1 \mathrm{~h}$ (Mulnavey, 1996), filtered, and $\mathrm{N}_{-} \mathrm{NH}_{4}{ }^{+}$was measured with a Skalar auto-analyzer (segmented flux spectrophotometer) (SK Sisdeur, Holland).

Soils were fertilized with $\mathrm{N}$ rates of 0,80 , and $160 \mathrm{~kg}$ $\mathrm{ha}^{-1}$ as urea in the five locations. In addition, $60 \mathrm{~kg} \mathrm{P}_{2} \mathrm{O}_{5}$ and $60 \mathrm{~kg} \mathrm{~K}_{2} \mathrm{O}$ were applied as triple superphosphate and potassium chloride, respectively. These $\mathrm{N}$ rates were chosen because they were verified in previous
Table 1. Soil physical and chemical properties $(0-20 \mathrm{~cm}$ depth).

\begin{tabular}{|c|c|c|c|c|c|}
\hline \multirow[b]{2}{*}{ Parameters } & \multirow[b]{2}{*}{ Quilmen } & \multicolumn{4}{|c|}{ Rice paddy soil } \\
\hline & & Achibueno & Parral & Quella1 & Quella2 \\
\hline Clay, \% & 31.4 & 34.4 & 34.1 & 36.1 & 40.4 \\
\hline Silt, \% & 31.6 & 41.3 & 38.8 & 32.6 & 30.7 \\
\hline Sand, $\%$ & 37.0 & 24.3 & 27.1 & 31.2 & 28.9 \\
\hline Bulk density, $\mathrm{g} \mathrm{cm}^{-3}$ & 1.77 & 1.72 & 2.09 & 1.89 & 2.17 \\
\hline Total porosity, $\%$ & 33.2 & 35.1 & 22.3 & 28.7 & 18.1 \\
\hline pH (soil:water 1:5) & 5.5 & 5.8 & 5.2 & 5.7 & 5.6 \\
\hline Organic matter, $\mathrm{g} \mathrm{kg}^{-1}$ & 40.0 & 29.0 & 48.0 & 22.0 & 26.0 \\
\hline $\mathrm{EC}, \mathrm{dS} \mathrm{m}^{-1}$ & 0.08 & 0.04 & 0.10 & 0.04 & 0.08 \\
\hline Ratio C:N & 10.8 & 12.0 & 12.0 & 11.4 & 12.2 \\
\hline Mineralized $\mathrm{N}, \mathrm{mg} \mathrm{kg}^{-1}$ & 70.6 & 51.0 & 101.8 & 46.5 & 67.6 \\
\hline POlsen, $\mathrm{mg} \mathrm{kg}^{-1}$ & 13.2 & 4.3 & 12.0 & 4.9 & 7.0 \\
\hline Exchangeable $\mathrm{K}, \mathrm{cmol}_{\mathrm{c}} \mathrm{kg}^{-1}$ & 0.44 & 0.24 & 0.26 & 0.17 & 0.21 \\
\hline Exchangeable Ca, $\mathrm{cmol}_{\mathrm{c}} \mathrm{kg}^{-1}$ & 7.72 & 7.27 & 6.26 & 7.80 & 7.05 \\
\hline Exchangeable $\mathrm{Mg}, \mathrm{cmol}_{\mathrm{c}} \mathrm{kg}^{-1}$ & 2.65 & 2.75 & 2.30 & 3.26 & 3.60 \\
\hline Exchangeable $\mathrm{Na}, \mathrm{cmol}_{\mathrm{c}} \mathrm{kg}^{-1}$ & 0.31 & 0.22 & 0.30 & 0.26 & 0.22 \\
\hline Exchangeable $\mathrm{Al}, \mathrm{cmol}_{\mathrm{c}} \mathrm{kg}^{-1}$ & 0.09 & 0.05 & 0.12 & 0.02 & 0.02 \\
\hline Available Fe, $\mathrm{mg} \mathrm{kg}^{-1}$ & 127.0 & 173.0 & 266.0 & 47.5 & 137.0 \\
\hline Available Mn, $\mathrm{mg} \mathrm{kg}^{-1}$ & 90.0 & 159.0 & 189.0 & 77.6 & 198.0 \\
\hline Available $\mathrm{Zn}, \mathrm{mg} \mathrm{kg}^{-1}$ & 0.8 & 0.9 & 2.3 & 0.6 & 1.8 \\
\hline Available $\mathrm{Cu}, \mathrm{mg} \mathrm{kg}^{-1}$ & 3.0 & 4.3 & 5.1 & 3.6 & 3.9 \\
\hline Available B, $\mathrm{mg} \mathrm{kg}^{-1}$ & 0.19 & 0.11 & 0.19 & 0.05 & 0.15 \\
\hline Available $\mathrm{S}, \mathrm{mg} \mathrm{kg}^{-1}$ & 27.0 & 14.6 & 31.5 & 1.0 & 14.9 \\
\hline
\end{tabular}

experiments in the same study area where they produced a range of crop responses (Ortega, 2007; Hirzel et al., 2011a). Each experimental unit was $15 \mathrm{~m}^{2}$ and all plots were cultivated under traditional agronomic management to optimize crop growth in accordance with standard agronomic practices for rice crops in central Chile. Nitrogen (urea) was applied three times: $33 \%$ the day prior to sowing, $33 \%$ at tillering, and $34 \%$ at initial panicle (Hirzel et al., 2011a). 'Zafiro-INIA' (japonica type, second most used variety in Chile) was chosen and seeds were pre-germinated $2 \mathrm{~d}$ before sowing. Seeding rate was $160 \mathrm{~kg} \mathrm{ha}^{-1}$ in all experimental locations. Weed control after emergence consisted of a combination of herbicides: Penoxsulam (3-(2,2-difluoroethoxy)- $N-(5,8-$ dimethoxy[1,2,4]triazolo[1,5-c]pyrimidin-2-yl)- $\alpha, \alpha, \alpha-$ trifluorotoluene-2-sulfonamide, Ricer $240 \mathrm{~g} \mathrm{~L}^{-1}$ ), MCPA (4-chloro- $O$-tolyloxyacetic acid, MCPA $750 \mathrm{SL} 750 \mathrm{~g} \mathrm{~L}^{-1}$ ), and Bentazon (3-isopropyl-1H-2,1,3-benzothiadiazin4(3H)-one 2,2-dioxide, Basagran $480 \mathrm{~g} \mathrm{~L}^{-1}$ ) at rates of $0.03,0.19$, and $0.72 \mathrm{~kg}$ ai $\mathrm{ha}^{-1}$, respectively. The crop was harvested at grain maturity $(20 \%$ grain moisture content). The evaluated parameters were total DM production, $\mathrm{N}, \mathrm{P}, \mathrm{K}, \mathrm{Ca}$, and $\mathrm{Mg}$ concentrations, and NARE. Dry matter production and nutrient concentration were evaluated from a $1 \times 2 \mathrm{~m}$ sample from each plot harvested at grain maturity. Dried subsamples were ground with a mill, passed though a $2 \mathrm{~mm}$ sieve, and analyzed. Total $\mathrm{N}$ was determined by the macro-Kjeldahl procedure, whereas total $\mathrm{K}, \mathrm{Ca}$, and $\mathrm{Mg}$ were determined by atomic emission $(\mathrm{K})$ and atomic absorption $(\mathrm{Ca}$ and $\mathrm{Mg}$ ) spectrophotometry after dry-ashing at $500{ }^{\circ} \mathrm{C}$ and acid digestion $(2 \mathrm{M} \mathrm{HCl}$ ). Phosphorus was measured in the same extracts by colorimetry following the molybdate ascorbic acid method. Furthermore, NARE was calculated 
as the difference between total $\mathrm{N}$ uptake of each fertilizer treatment and control divided by total applied $\mathrm{N}$ (Rees and Castle, 2002):

$$
\mathrm{NARE}=[(\mathrm{A}-\mathrm{B}) / \mathrm{C}]
$$

where $\mathrm{A}$ is $\mathrm{N}$ uptake for the treatment $\left(\mathrm{kg} \mathrm{ha}^{-1}\right), \mathrm{B}$ is $\mathrm{N}$ uptake for the control $\left(\mathrm{kg} \mathrm{ha}^{-1}\right)$, and $\mathrm{C}$ is applied $\mathrm{N}$ for the treatment $\left(\mathrm{kg} \mathrm{ha}^{-1}\right)$.

A split-plot experimental design was used where the principal plot was the soil (5) and $\mathrm{N}$ rates (3) were the split-plots with four replicates for each experimental unit. Results were analyzed by ANOVA and Tukey's test ( $\mathrm{p}=$ 0.05 ) by the SAS general model procedure (SAS Institute, 1989). Effects were compared by orthogonal contrasts when sources of variation interacted.

\section{RESULTS AND DISCUSSION}

The physical and chemical properties of each soil exhibited few limitations for rice cultivation; some important properties were low B concentration in all soils, low $\mathrm{P}$ in Achibueno and Quella1, low K in Achibueno, Parral, Quella1, and Quella2, low S in Quella1, and acidity in Parral (Table 1). Mineralized N also showed differences among soils (Table 1), which is directly related to crop response to applied $\mathrm{N}$ (yield increased for each $\mathrm{kg}$ of applied N) (Hirzel and Rodríguez, 2013).

Grain yield in the experiment fluctuated between 5.1 and 11.5 $\mathrm{Mg} \mathrm{ha}^{-1}$ (Hirzel and Rodríguez, 2013; data not shown). These yields were similar to those found by several authors for the same study area (Ortega, 2007; Artacho et al., 2009; Hirzel et al., 2011a).

The statistical analysis of total DM production (Table 2 ) indicates that this parameter was affected by both soil type and $\mathrm{N}$ rates used $(\mathrm{p}<0.01)$; however, there was no interaction between these sources of variation. The soils in Parral reached the highest total DM production (Table 3 and Figure 1); Quella1 and Quella2 followed and outperformed Quilmen, while only Quella2 surpassed Achibueno (Table 3 and Figure 1). These differences in DM production are due to climatic and soil properties, which have been recorded by other authors for the same study area (Ortega, 2007; Artacho et al., 2009; Hirzel et al., 2011a; 2011b; Hirzel and Rodríguez, 2013) and other geographic areas (Ying et al., 1998; Matsunami et al., 2009; Taylaran et al., 2009). Regarding N rates used, contrasts indicate a highly significant effect in all the

Table 2. Significance levels of the evaluated parameters.

\begin{tabular}{lccccccc}
\hline $\begin{array}{l}\text { Sources of } \\
\text { variability }\end{array}$ & $\mathrm{DM}$ & $\mathrm{N}$ & $\mathrm{P}$ & $\mathrm{K}$ & $\mathrm{Ca}$ & $\mathrm{Mg}$ & NARE $^{3}$ \\
\hline Soils $(\mathrm{S})^{1}$ & $* *$ & $* *$ & $*$ & $\mathrm{NS}$ & $* *$ & $* *$ & $*$ \\
$\mathrm{~N}$ rate $(\mathrm{N})^{2}$ & $* *$ & $\mathrm{NS}$ & $* *$ & $* *$ & $\mathrm{NS}$ & $* *$ & $\mathrm{NS}$ \\
$\mathrm{S} * \mathrm{~N}$ & $\mathrm{NS}$ & $\mathrm{NS}$ & $\mathrm{NS}$ & $\mathrm{NS}$ & $\mathrm{NS}$ & $*$ & $\mathrm{NS}$ \\
\hline
\end{tabular}

${ }^{1}$ Five soil types: Achibueno, Quilmen, Parral, Quella1, and Quella2.

${ }^{2}$ Three $\mathrm{N}$ rates; 0,80 , and $160 \mathrm{~kg} \mathrm{ha}^{-1}$.

${ }^{3}$ Two $\mathrm{N}$ rates; 80 and $160 \mathrm{~kg} \mathrm{ha}^{-1}$.

*Significant at $\mathrm{p}<0.05 ; * *$ Significant at $\mathrm{p}<0.01$; NS: non significant; NARE: $\mathrm{N}$ apparent recovery efficiency.
Table 3. Significance levels for contrast analysis of sources of variation of evaluated parameters.

\begin{tabular}{lccccccc}
\hline Contrast & DM & N & P & K & Ca & Mg & NARE $^{1}$ \\
\hline Soil & & & & & & & \\
Achibueno-Quilmen & NS & $* *$ & NS & NS & $*$ & NS & $* *$ \\
Achibueno-Parral & $* *$ & NS & NS & NS & $* *$ & $*$ & NS \\
Achibueno-Quella 1 & NS & $* *$ & NS & NS & NS & $* *$ & NS \\
Achibueno-Quella 2 & $*$ & $* *$ & $*$ & NS & NS & $*$ & NS \\
Quilmen-Parral & $* *$ & $* *$ & NS & NS & NS & $* *$ & $* *$ \\
Quilmen-Quella 1 & $* *$ & $* *$ & NS & NS & $* *$ & $* *$ & $* *$ \\
Quilmen-Quella 2 & $* *$ & $* *$ & $*$ & NS & NS & NS & $* *$ \\
Parral-Quella 1 & $* *$ & $* *$ & NS & NS & $* *$ & $* *$ & NS \\
Parral-Quella 2 & $*$ & $*$ & NS & NS & NS & $* *$ & NS \\
Quella1-Quella 2 & NS & NS & NS & NS & $* *$ & $*$ & NS \\
N-rates, kg ha-1 & & & & & & & \\
$\quad 0-80$ & $* *$ & NS & $*$ & $* *$ & NS & NS & - \\
$0-160$ & $* *$ & NS & $* *$ & $* *$ & NS & $* *$ & - \\
$80-160$ & $* *$ & NS & NS & $*$ & NS & $* *$ & NS \\
\hline
\end{tabular}

*Significant at $\mathrm{p}<0.05$.

$* *$ Significant at $\mathrm{p}<0.01$

${ }^{1}$ NARE: N apparent recovery efficiency.

NS: non significant; -: without mean comparison.

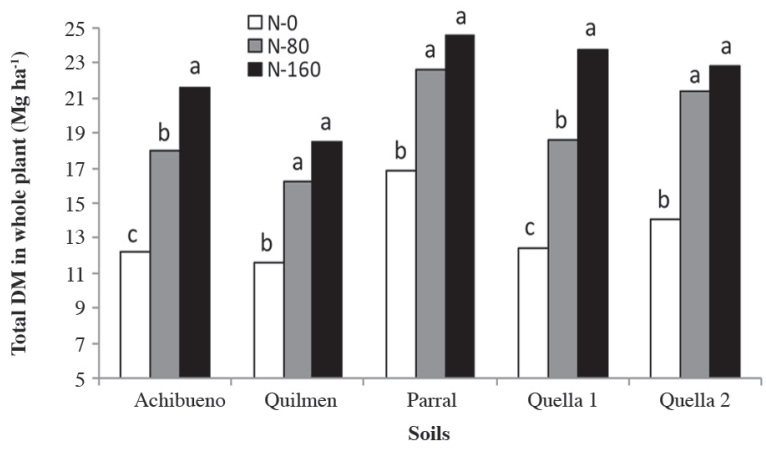

Different letters over the bars of the same soil indicate significant differences according to Tukey's test $(\mathrm{p}<0.05)$.

N-0: $0 \mathrm{~kg} \mathrm{~N} \mathrm{ha}^{-1}$; N-80: $80 \mathrm{~kg} \mathrm{~N} \mathrm{ha}^{-1}$; N-160: $160 \mathrm{~kg} \mathrm{~N} \mathrm{ha}^{-1}$.

Figure 1. Whole-plant total dry matter production in five paddy rice soils.

comparisons (Table 3). Although applying $\mathrm{N}$ produces higher total DM production than in the controls with no applied $\mathrm{N}$, there is no difference between the 80 and 160 $\mathrm{kg} \mathrm{N} \mathrm{ha}{ }^{-1}$ rates in Quilmen, Parral, and Quella2 when isolating the effects in each soil (Figure 1). This lower response in total DM production obtained in Quilmen, Parral, and Quella2 is explained by their chemical properties; with the exception of $\mathrm{B}$ concentration, these did not exhibit limitations for rice (Table 1). Another very important aspect in this response effect is mineralized $\mathrm{N}$ concentration, which was the highest in these three soils (Table 1); this is closely related to rice crop response to the applied $\mathrm{N}$ rate (Hirzel and Rodríguez, 2013).

Plant $\mathrm{N}$ concentration was only affected by soil type ( $\mathrm{p}$ $<0.01$ ) (Table 2) with differences among some soils (Table 3 ); it fluctuated between 5.1 and $7.7 \mathrm{~g} \mathrm{~kg}^{-1} \mathrm{DM}$ throughout the experiment and in the treatments with $\mathrm{N}$. These values were similar to those inferred in reports by Artacho et al. (2009) for N concentration in grain and straw of 'DiamanteINIA' for the same area under study and lower than those 
inferred by Taylaran et al. (2009). The highest values were obtained in Quella1 and Quella2, which outperformed Parral and Achibueno; there were no differences between the latter two $(\mathrm{p}>0.05)$ which surpassed Quilmen (Table 3 and Figure 2). Regarding $N$ rates used (Figure 2), no differences were found in $\mathrm{N}$ concentrations obtained ( $\mathrm{p}>$ 0.05 ) when isolating the effects in each soil; a quantitative increase of $\mathrm{N}$ concentration was directly proportional to the applied $\mathrm{N}$ rate in four soils. Given that this increase in $\mathrm{N}$ concentration in the treatments that received $\mathrm{N}(80$ and $160 \mathrm{~kg} \mathrm{ha}^{-1}$ ) did not increase grain yield (Hirzel and Rodríguez, 2013; data not shown), luxury consumption occurred. However, because of the $\mathrm{N}$ concentration variability obtained among the different soils and the absence of a significant difference with the control without $\mathrm{N}$ in each soil, an adequate concentration value cannot be suggested for this cultivar ('Zafiro-INIA'). This $\mathrm{N}$ concentration variability in rice among environments, as well as seasons, in response to adding $\mathrm{N}$ has also been reported by some authors (Matsunami et al., 2009; Taylaran et al., 2009).

Plant $\mathrm{P}$ concentration was affected by the soil and $\mathrm{N}$ rate with no interaction between these sources of variation

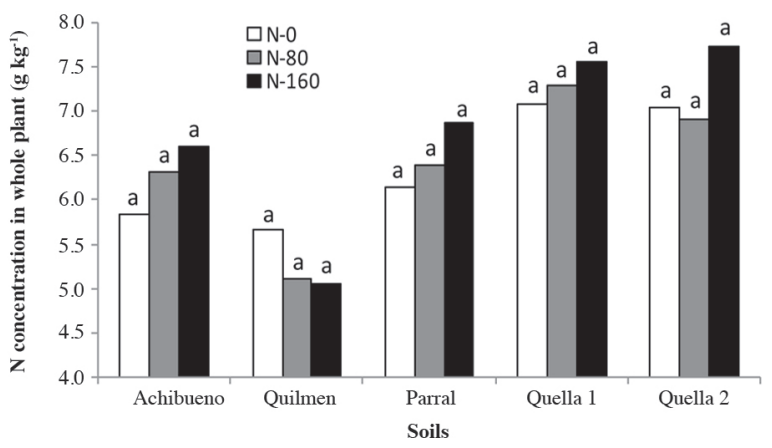

Different letters over the bars of the same soil indicate significant differences according to Tukey's test $(\mathrm{p}<0.05)$.

N-0: 0 kg N ha-1 ${ }^{-1}-80: 80 \mathrm{~kg} \mathrm{~N} \mathrm{ha}^{-1}$; N-160: $160 \mathrm{~kg} \mathrm{~N} \mathrm{ha}^{-1}$

Figure 2. Rice whole-plant nitrogen concentration in five paddy rice soils.

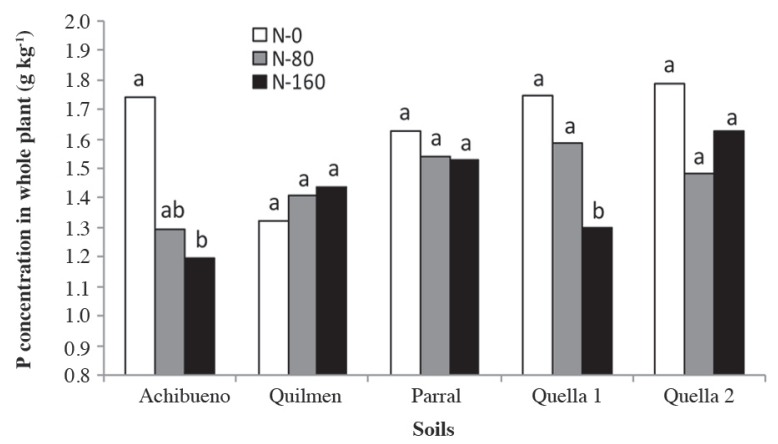

Different letters over the bars of the same soil indicate significant differences according to Tukey's test $(\mathrm{p}<0.05)$.

N-0: 0 kg N ha' ${ }^{-1}$ N-80: $80 \mathrm{~kg} \mathrm{~N} \mathrm{ha}^{-1}$; N-160: $160 \mathrm{~kg} \mathrm{~N} \mathrm{ha}^{-1}$.

Figure 3. Rice whole-plant phosphorus concentration in five paddy rice soils.
(Table 2); it fluctuated between 1.3 and $1.8 \mathrm{~g} \mathrm{~kg}^{-1} \mathrm{DM}$ (Figure 3). There were only differences among three soils where Quella2 outperformed Achibueno and Quilmen ( $p$ $<0.05$ ) and no differences were found in the latter two (Table 3 and Figure 3). Regarding applied $\mathrm{N}$ rates, there was no difference among treatments that received $\mathrm{N}$ and the control without $\mathrm{N}$ (Table 3). When isolating the effect in each soil, this difference was verified in Achibueno and Quella1 (Figure 3) where P concentration was inversely proportional to the $\mathrm{N}$ rate used. This effect can be explained by the dilution factor that is produced with the increase in total DM production obtained in response to applying increasing $\mathrm{N}$ rates in these soils (Figure 1). In contrast with these results, Kapoor et al. (2008) have reported increases in $\mathrm{P}$ uptake in rice plants when both crop $\mathrm{N}$ and $\mathrm{P}$ rates increased.

Plant $\mathrm{K}$ concentration was only affected by the $\mathrm{N}$ rates used (Tables 2 and 3) and fluctuated between 5.4 and $10.8 \mathrm{~g} \mathrm{~kg}^{-1}$ DM (Figure 3 and Table 3). A difference was detected in Parral and Quella2 (Figure 4) where the N rate was inversely proportional to the $\mathrm{K}$ concentration obtained when the effects of the $\mathrm{N}$ rate in each soil were isolated. Similarly, this same tendency was observed in most soils. As it occurred for $\mathrm{P}$, this result can be explained by a dilution effect associated with the increase in total DM production by adding increasing $\mathrm{N}$ rates (Figure 1); four of these soils had an exchangeable $\mathrm{K}$ concentration less than $0.3 \mathrm{cmol}_{(+)} \mathrm{kg}^{-1}$ (Table 1), which is the critical value determined for rice soils in Chile (Hirzel and Cordero, 2011). Kapoor et al. (2008) have reported increases in $K$ uptake by rice plants when the $\mathrm{N}$ rate or the joint $\mathrm{N}$ and $\mathrm{P}$ rate increased in the crop.

Plant Ca concentration was only affected by soil type $(\mathrm{p}<0.01)$ (Table 2) and with differences among some soils (Table 3); it fluctuated between 1.68 and $2.57 \mathrm{~g} \mathrm{~kg}^{-1}$ DM throughout the experiment, while this concentration in the $\mathrm{N}$-fertilized treatments reached a maximum of 2.42 $\mathrm{g} \mathrm{kg}^{-1} \mathrm{DM}$ (Figure 5). The contrasts among soils indicated that the highest plant $\mathrm{Ca}$ concentration was obtained in

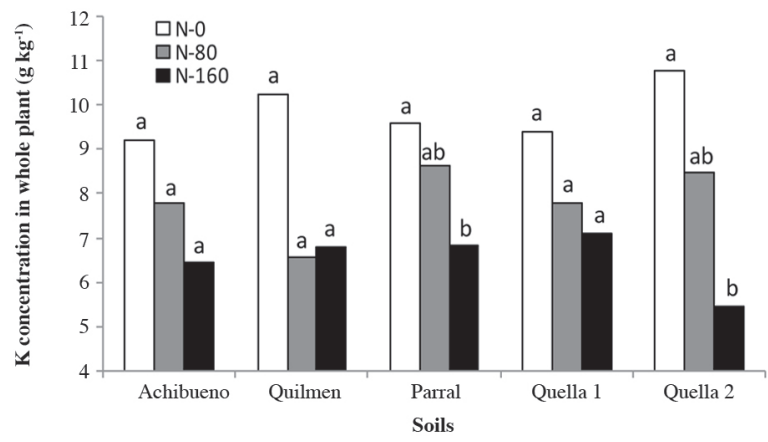

Different letters over the bars of the same soil indicate significant differences according to Tukey's test $(\mathrm{p}<0.05)$.

N-0: 0 kg N ha-1; N-80: 80 kg N ha' ; N-160: $160 \mathrm{~kg} \mathrm{~N} \mathrm{ha}^{-1}$.

Figure 4. Rice whole-plant potassium concentration in five paddy rice soils. 
Quilmen and Parral; these outperformed Achibueno and Quella1, while Quella2 exhibited a Ca concentration similar to Parral and Achibueno, which was higher than Quella1 ( $<0.01)$ (Table 3 and Figure 5). The contrasts among $\mathrm{N}$ rates did not affect Ca concentration $(\mathrm{p}>0.05)$ (Table 3); for each soil, the effect of the $\mathrm{N}$ rate on this nutritional parameter of the plant was not observed (Figure 5) and this is associated with the adequate $\mathrm{Ca}$ concentration in the soil (Table 1). In quantitative terms, a reduced $\mathrm{Ca}$ concentration in response to applied $\mathrm{N}$ at any of its rates was observed in Achibueno, Quilmen, and Quella2 (Figure 5); this was associated with a dilution effect due to the increase in total DM production (Figure 1). No limitations for this nutrient were observed in the chemical properties of these soils (Table 1) according to Hirzel and Cordero (2011). In contrast, this dilution effect was not observed in Parral and Quella1 (Figure 5) although they showed a high total DM production response for the $\mathrm{N}$ rates used (Figure 1).

Plant $\mathrm{Mg}$ concentration was affected by both sources of variation as well as their interaction (Table 2). This concentration fluctuated between 0.81 and $1.45 \mathrm{~g} \mathrm{~kg}^{-1}$ DM (Figure 6). Contrasting the evaluated soils showed a difference in most of them, with the exception between Achibueno and Quilmen and between Quilmen and Quella2 (Table 3). The highest whole-plant Mg concentration was obtained in Parral followed by Achibueno, Quilmen, Quella2, and Quella1 (Table 3 and Figure 6). The contrast among $\mathrm{N}$ rates used only showed a difference between the control without $\mathrm{N}$ and the $160 \mathrm{~kg} \mathrm{~N} \mathrm{ha}^{-1}$ treatment, as well as between both treatments fertilized with $\mathrm{N}$ (Table $3)$. This difference was only noted in Parral and Quella2 (Figure 6) with a directly proportional increase in the $\mathrm{N}$ rate in Parral and an erratic effect in Quella2 (Figure 6) when the effects in each soil were isolated. The absence of differences in plant $\mathrm{Mg}$ concentrations can be a response to the adequate concentration of this nutrient in all soils (Table 1).

The value of NARE in this experiment fluctuated

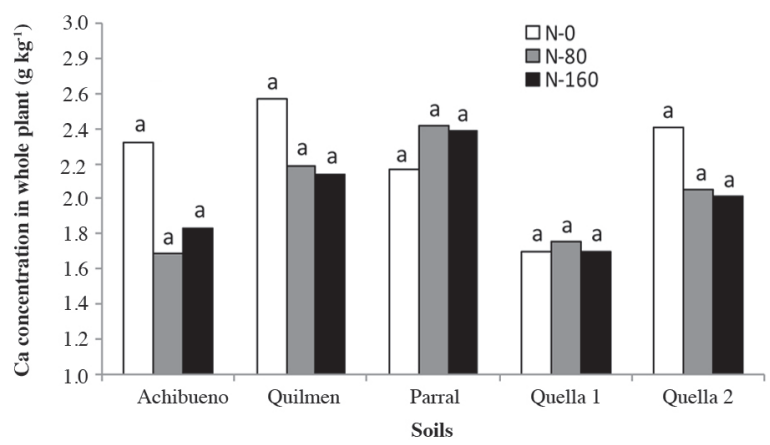

Different letters over the bars of the same soil indicate significant differences according to Tukey's test $(\mathrm{p}<0.05)$.

N-0: 0 kg N ha ${ }^{-1}$; N-80: $80 \mathrm{~kg} \mathrm{~N} \mathrm{ha}^{-1}$; N-160: $160 \mathrm{~kg} \mathrm{~N} \mathrm{ha}^{-1}$.

Figure 5. Rice whole-plant calcium concentration in five paddy rice soils.

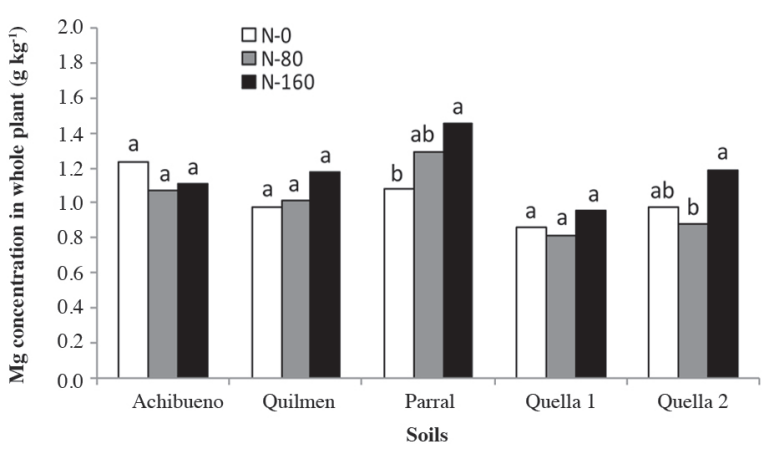

Different letters over the bars of the same soil indicate significant differences according to Tukey's test $(\mathrm{p}<0.05)$.

N-0: $0 \mathrm{~kg} \mathrm{~N} \mathrm{ha}^{-1}$; N-80: $80 \mathrm{~kg} \mathrm{~N} \mathrm{ha}^{-1}$; N-160: $160 \mathrm{~kg} \mathrm{~N} \mathrm{ha}^{-1}$.

Figure 6. Rice whole-plant magnesium concentration in five paddy rice soils.

between $17 \%$ and $60 \%$ and most values were over $42 \%$ with a mean of $45 \%$ for the entire experiment (Figure 7); there were differences only among soils $(\mathrm{p}<0.05)$ (Tables 1 and 3). When soils were contrasted, Quilmen exhibited the lowest NARE $(\mathrm{p}<0.01)$ associated with its lower whole-plant $\mathrm{N}$ concentrations (Figure 2), while there was no difference among the other soils (Table 3 and Figure 7). There was no difference in the soils (Figure 7) when the effects of the $\mathrm{N}$ rates used in each soil were isolated. This is explained by the high coefficients of variation (data not shown) that were greater than $40 \%$. As expected, there was a tendency to a lower NARE when using the highest $\mathrm{N}$ rate (Figure 7), and the mean NARE obtained with each N rate was $49 \%$ and $41 \%$ for the 80 and $160 \mathrm{~kg} \mathrm{~N}^{-1}$ rates, respectively. These values were similar to those pointed out by Huang et al. (2008) for two rice cultivars with different $\mathrm{N}$ fertilization treatments (from 90 to $165 \mathrm{~kg} \mathrm{~N}$ ha $^{-1}$ ) in China as well as Taylaran et al. (2009) in Japan for six rice cultivars managed with and without conventional partialized $\mathrm{N}$ fertilization $\left(70 \mathrm{~kg} \mathrm{~N} \mathrm{ha}^{-1}\right)$. Moreover, these values are indicated in the historical records of organic barnyard $\mathrm{N}$ applications $\left(152 \mathrm{~kg} \mathrm{~N} \mathrm{ha}^{-1}\right)$ in the $20 \mathrm{yr}$ prior to the two experimental seasons.

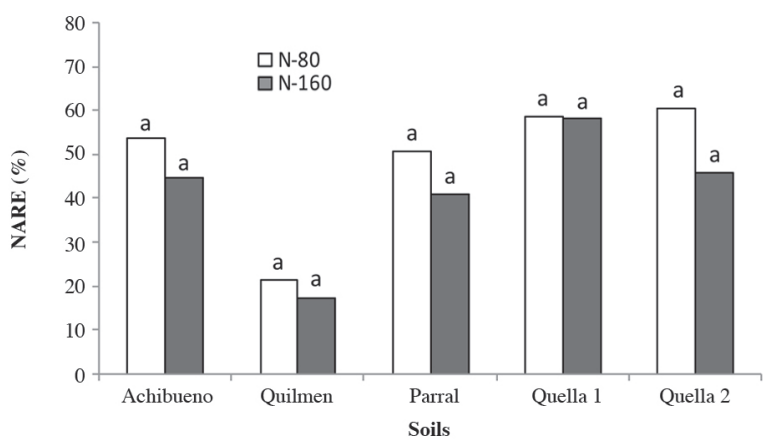

Different letters over the bars of the same soil indicate significant differences according to Tukey's test $(\mathrm{p}<0.05)$.

N-80: $80 \mathrm{~kg} \mathrm{~N} \mathrm{ha}^{-1}$; N-160: $160 \mathrm{~kg} \mathrm{~N} \mathrm{ha}^{-1}$.

Figure 7. Nitrogen apparent recovery efficiency (NARE) of rice whole-plant in five paddy rice soils. 


\section{CONCLUSIONS}

Applying increasing $\mathrm{N}$ rates in the 'Zafiro-INIA' rice crop positively affected total DM production and its $\mathrm{P}$, $\mathrm{K}$, and $\mathrm{Mg}$ concentrations, while whole-plant $\mathrm{N}$ and $\mathrm{Ca}$ concentrations were not affected. Whole-plant $\mathrm{P}$ and $\mathrm{K}$ concentrations had different responses when $\mathrm{N}$ was added to each soil associate to its chemical properties. The $\mathrm{Mg}$ concentration exhibited an erratic effect, but it was not affected by the $\mathrm{N}$ rate in most soils. The value of NARE was not affected by the applied $\mathrm{N}$ rate, but the highest value was generally achieved with the lowest $\mathrm{N}$ rate used. Finally, the results of this study allow the characterization of whole-plant macronutrient composition of 'ZafiroINIA', which corresponds to 5.1-7.7 g N, 1.3-1.8 g P, 5.4$10.8 \mathrm{~g} \mathrm{~K}, 1.68-2.57 \mathrm{~g} \mathrm{Ca}$, and $0.81-1.45 \mathrm{~g} \mathrm{Mg} \mathrm{kg}^{-1}$ total DM.

\section{ACKNOWLEDGEMENTS}

This study was funded by FONDECYT 11110232 Project of the Comisión Nacional de Investigación Científica (CONICYT), Chile.

\section{LITERATURE CITED}

Angus, J.F., M. Ohnishi, T. Horie, and L. Williams. 1994. A preliminary study to predict net nitrogen mineralization in a flooded rice soil using anaerobic incubation. Australian Journal of Experimental Agriculture 34:995-999.

Artacho, P., C. Bonomelli, and F. Meza. 2009. Nitrogen application in irrigated rice growth in Mediterranean conditions: Effects on grain yield, dry matter production, nitrogen uptake, and nitrogen use efficiency. Journal of Plant Nutrition 32:1574-1593.

Bouman, B.A.M., E. Humphreys, T.P. Tuong, R. Barker, and L.S. Donald. 2007. Rice and water. Advances in Agronomy 92:187237.

Bushong, J.T., R.J. Norman, W.J. Ross, N.A. Slaton, C.E. Wilson, and E.E. Gbur. 2007. Evaluation of several indices of potentially mineralizable soil nitrogen. Communications in Soil Science and Plant Analysis 38:2799-2813

CIREN. 1997. Descripción de suelos, materiales y símbolos, estudio agrológico VII Región. Publicación No 117. 659 p. Centro de Información de Recursos Naturales (CIREN), Ministerio de Agricultura, Santiago, Chile.

Cordero-Vásquez, A., and J.I. Murillo-Vargas. 1990. Removal of nutrients by rice cultivar CR 1821 under flood irrigation. Agronomía Costarricense 14:79-83.

De-Xi, L., F. Xiao-Hui, H. Fena, Z. Hong-Tao, and L. Jia-Fa. 2007. Ammonia volatilization and nitrogen utilization efficiency in response to urea application in rice fields of the Taihu Lake region, China. Pedosphere 15:639-645.

FAO. 2004. Estimaciones globales de las emisiones gaseosas de $\mathrm{NH}_{3}$, NO y $\mathrm{N}_{2} \mathrm{O}$ provenientes de las tierras agrícolas. FAO, Roma, Italia. p. 1-22. Available at ftp://ftp.fao.org/docrep/fao/009/ y2780s/y2780s00.pdf

Hirzel, J., y K. Cordero. 2011. Fertilización del cultivo de arroz. In Hirzel, J. (ed.) Fertilización de cultivos en Chile. Colección Libros INIA No 28. 434 p. Instituto de Investigaciones Agropecuarias INIA, Centro Regional de Investigación Quilamapu, Chillán, Chile.

Hirzel, J., K. Cordero, C. Fernández, J. Acuña, M. Sandoval, and E. Zagal. 2011b. Soil potentially mineralizable nitrogen and its relation to rice production and nitrogen needs in two paddy rice soils of Chile. Journal of Plant Nutrition 35:396-412.

Hirzel, J.,A. Pedreros, and K. Cordero. 2011a. Effect of nitrogen rates and split nitrogen fertilization on grain yield and its components in flooded rice. Chilean Journal of Agricultural Research 71:437444.

Hirzel, J., and F. Rodríguez. 2013. Response of rice to increasing nitrogen rates in five soils with different mineralizable nitrogen levels. Journal of Plant Nutrition (In Press).

Hirzel, J., and N. Stolpe. 2013. Anaerobic incubation without shaking over a prolonged period as a method to determine mineralizable nitrogen in rice soils. Geoderma (In Press).

Huang, J., F. He, K. Cui, R. Buresh, B. Xu, W. Gong, et al. 2008. Determination on optimal nitrogen rate for rice varieties using a chlorophyll meter. Field Crops Research 105:70-80.

Jing, Q., B. Bouman, H. van Keulen, H. Hengsdijk, W. Cao, and T. Dai. 2008. Disentangling the effect of environmental factors on yield and nitrogen uptake of irrigated rice in Asia. Agricultural System 98:177-188.

Juliano, B.O. 1993. Rice in human nutrition. FAO Food and Nutrition Series $N^{\circ} 26.162$ p. FAO, Rome, Italy. International Rice Research Institute (IRRI), Los Baños, Laguna, Philippines.

Kapoor, V., U. Singh, S.K. Patil, H. Magre, L.K. Shrivastava, R.O. Das, et al. 2008. Rice growth, grain yield, and floodwater nutrient dynamics as affected by nutrient placement method and rate. Agronomy Journal 100:526-536.

Matsunami, M., T. Matsunami, and M. Kokubun. 2009. Growth and yield of new rice for Africa (NERICAs) under different ecosystems and nitrogen levels. Plant Production Science 12:381389.

Mengel, K., and E. Kirkby. 1987. Principles of plant nutrition. $4^{\text {th }}$ ed 686 p. Internal Potash Institute, Worblaufen-Bern, Switzerland.

Mulnavey, L.R. 1996. Nitrogen inorganic forms. p. 1123-1184 In J.M. Bartels (ed.) Methods of soil analysis part 3. Chemical Methods. American Society of Agronomy, Madison, Wisconsin, USA.

Ortega, R. 2007. Analysis of factors affecting spikelet sterility in flooded rice under field conditions in Chile. Archives of Agronomy and Soil Science 53:183-192.

Rees, R., and K. Castle. 2002. Nitrogen recovery in soils amended with organic manures combined with inorganic fertilisers. Agronomie 22:739-746.

Sadzawka, A., M.A. Carrasco, R. Grez, M. Mora, H. Flores, y A. Neaman. 2006. Métodos de análisis recomendados para los suelos de Chile. Serie Actas INIA N ${ }^{\circ} 34.164$ p. Instituto de Investigaciones Agropecuarias INIA, Santiago, Chile.

Sahrawat, K. 2006. Organic matter and mineralizable nitrogen relationships in wetland rice soils. Communications in Soil Science and Plant Analysis 37:787-796.

SAS Institute. 1989. Usage and reference. Version 6. 501 p. SAS Institute, Cary, North Carolina, USA.

Scott, D., A. McLarren, and J. Burger. 2005. Rapid indices of potential nitrogen mineralization for intensively managed hardwood plantations. Communications in Soil Science and Plant Analysis 36:1421-1434.

Soon, Y., A. Haq, and M. Arshad. 2007. Sensitivity of nitrogen mineralization indicators to crop and soil management. Communications in Soil Science and Plant Analysis 38:20292043.

Taylaran, R., S. Ozawa, N. Miyamoto, T. Ookawa, T. Motobayashi, and T. Hirasawa. 2009. Performance of a high-yielding modern rice cultivar Takanari and several old and new cultivars grown with and without chemical fertilizer in a submerged paddy field. Plant Production Science 12:365-380.

Waring, S.A., and J.M. Bremner. 1964. Ammonium production in soil under water-logged conditions as an index of nitrogen availability. Nature 202:951-952.

Wienhold, B. 2007. Comparison of laboratory methods and an in situ method for estimating nitrogen mineralization in a irrigated silt-loam soil. Communications in Soil Science and Plant Analysis 38:1721-1732. 